\title{
Does Sacrococcygeal Angle Play a Role on Pilonidal Sinus Etiology?
}

\author{
Ramazan Eryilmaz', Arda Isik², Ismail Okan ${ }^{3}$, Tuna Bilecik $^{4}$, \\ Ensar Yekeler ${ }^{5}$, Mustafa Sahin ${ }^{3}$ \\ ${ }^{1}$ Department of General Surgery, Faculty of Medicine, Akdeniz University, \\ Antalya, Turkey; \\ ${ }^{2}$ Department of General Surgery, Faculty of Medicine, Erzincan University, \\ Erzincan, Turkey; \\ ${ }^{3}$ Department of General Surgery, Faculty of Medicine, Gaziosmanpasa University, \\ Tokat, Turkey; \\ ${ }^{4}$ General Surgery Clinic, Sinop State Hospital, Sinop, Turkey; \\ ${ }^{5}$ Department of Radiology, Faculty of Medicine, Istanbul University, Istanbul, Turkey
}

Received June 4, 2015; Accepted September 16, 2015.

Key words: Pilonidal sinus - Sacrococcygeal angle - Etiologic factor

Abstract: The predisposing factors for the development of sacrococcygeal pilonidal disease (SPD) still remain undetermined. Here, we investigate the sacrococcygeal angle as a possible predisposing factor for the development of disease. Consecutive male patients admitted to our clinic with the diagnosis of SPD were included. Sex, age and BMI matched healthy controls without SPD were enrolled to the study. The predefined sacrococcygeal angles of patients and controls were measured on lateral pelvic radiographs by a single experienced radiologist. Thirty patients were included in each group. Sacrococcygeal angles of patients and control group were measured as $37.3 \pm 14.5$ and $36.81 \pm 10.23$ in patients and controls, respectively. The difference with respect to sacrococcygeal angle was not statistically significant between two groups. Sacrococcygeal angle which is the main skeletal determinant of intergluteal sulcus is not a predisposing factor for the development of sacrococcygeal pilonidal disease.

Mailing Address: Arda Isik, MD., Department of General Surgery, Faculty of Medicine, Erzincan University, Mengucek Gazi Training and Research Hospital, Erzincan, Turkey; Mobile Phone: +90 53305807 07; e-mail: kararda@yahoo.com 


\section{Introduction}

Pilonidal disease mainly occurs in sacrococcygeal area affecting the natal clefts of the buttocks. Pilonidal disease occurs mainly in young male with a rate of approximately 26 per 100,000 population and compared with female, male gender is four times dominant (Isik et al., 2014). Although it has been described long time ago, many aspects of the disease are still under dispute (Hull and Wu, 2002; McCallum et al., 2007; Tejirian et al., 2007; Mahdy, 2008). Today a consensus has been reached stating that the disease is an acquired condition rather than congenital in origin (Raffman, 1959; Allen-Mersh, 1990; Hull and Wu, 2002; Chintapatla et al., 2003). Many conditions such as obesity, hairy body, male gender, poor hygiene, sitting in a vehicle for long time, presence of family history, thick local subcutaneous tissue were blamed as predisposing factors (Raffman, 1959; Allen-Mersh, 1990; Søndenaa et al., 1995; Akinci et al., 1999; Cubukcu et al., 2001; Hull and Wu, 2002; Chintapatla et al., 2003). The current explanation of pathogenesis is the formation of sinuses due to continuous irritation of hairs in sacrococcygeal area with induction of varying degrees of inflammation. The anatomical features of sacrococcygeal area may be responsible for the accumulation of hairs in intergluteal sulcus. Bascom (1990) reported that forces concentrate in a $1 \mathrm{~mm}^{2}$ area and angle at the lowest end of the sacrum were associated with the presence of pilonidal disease. We speculated that increased skeletal angulation may deepen the intergluteal sulcus where it renders individual more prone to pilonidal disease. The present study aimed to explore whether increased angulation of sacrococcygeal angle is associated with the disease.

\section{Patient and Methods}

This study was performed at Vakif Gureba Training and Research Hospital between March and April 2009. Consecutive thirty male patients diagnosed with sacrococcygeal pilonidal disease (SPD) and 30 healthy male subjects as a control group were included in this study. The subjects in control group were carefully examined to exclude the presence of asymptomatic disease. The female patients, individuals with trauma and/or SPD operation history, congenital skeletal deformities and existence of pilonidal abscess were excluded from the study. Both patients and control subjects were informed about the purpose and procedures of the study. Lateral pelvic radiography was applied in all patients. Sacrococcygeal angle was defined as an angle between the line which crosses the middle of the first constant coccygeal element and the line which combines the posteroinferior tip of first constant coccygeal element to the end point of last coccygeal element (Figure 1). The angle measurements were done by a single radiologist experienced in skeletal system in a blind fashion. Measurements were expressed as mean \pm standard deviation. Two sided Student's $t$-test was used to compare the measurements of angles between two groups. P-value of less than 0.05 was accepted as statistically significant. 


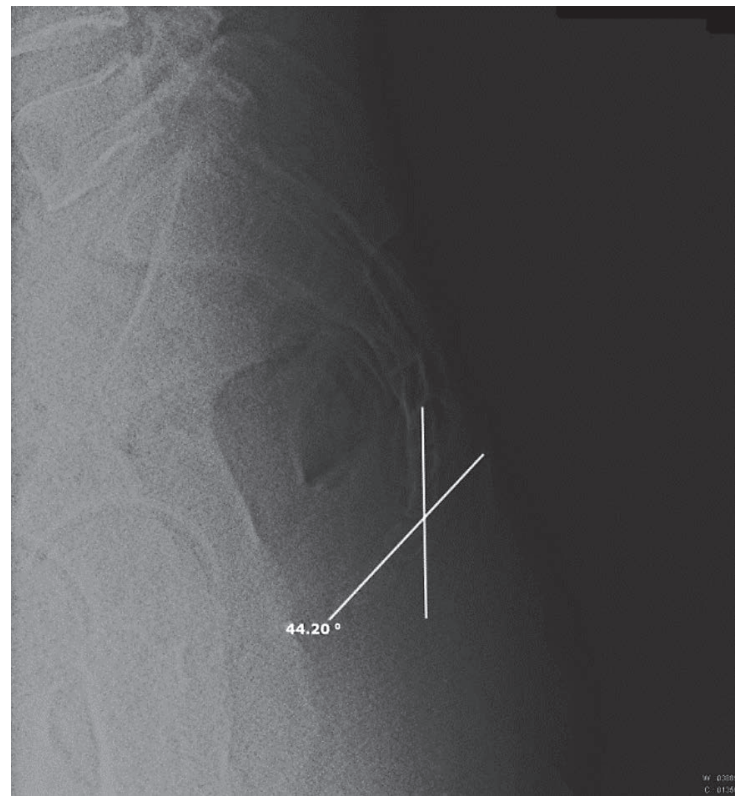

Figure 1 - Measurement of sacrococcygeal angle.

\section{Results}

Thirty patients complying with the inclusion criteria were enrolled to the study. Age, sex and BMI matched thirty patients were included as control group. Median age of patients at control and SPD groups were 23 (18-45) and 24 (18-48), respectively. The mean value of sacrococcygeal angle in patients was $37.30 \pm 14.50$. The same measurement in control group subjects was $36.86 \pm 10.23$. There was no significant difference between these values (Table 1). Figure 2 shows the measurements of sacrococcygeal angle belong to groups.

\section{Discussion}

There has been an enduring discussion over the etiology and treatment of pilonidal disease more than a century. The SPD disease was considered acquired rather than congenital. This notion was supported with various observations like the

\section{Table 1 - Demographic data and results}

\begin{tabular}{lccc}
\hline & Control & Pilonidal disease group & P-value \\
\hline Age (median) & $23(18-45)$ & $24(18-48)$ & $\mathrm{ns}$ \\
Gender & $M$ & $M$ & $\mathrm{~ns}$ \\
BMl (median) & $23(18-32)$ & $23(19-30)$ & $\mathrm{ns}$ \\
Sacrococcygeal angle (mean \pm SD) & $36.86 \pm 10.23$ & $37.30 \pm 14.50$ & $\mathrm{~ns}$ \\
\hline
\end{tabular}

BMI - body mass index; $M$ - male; ns - non-significant; SD - standard deviation 


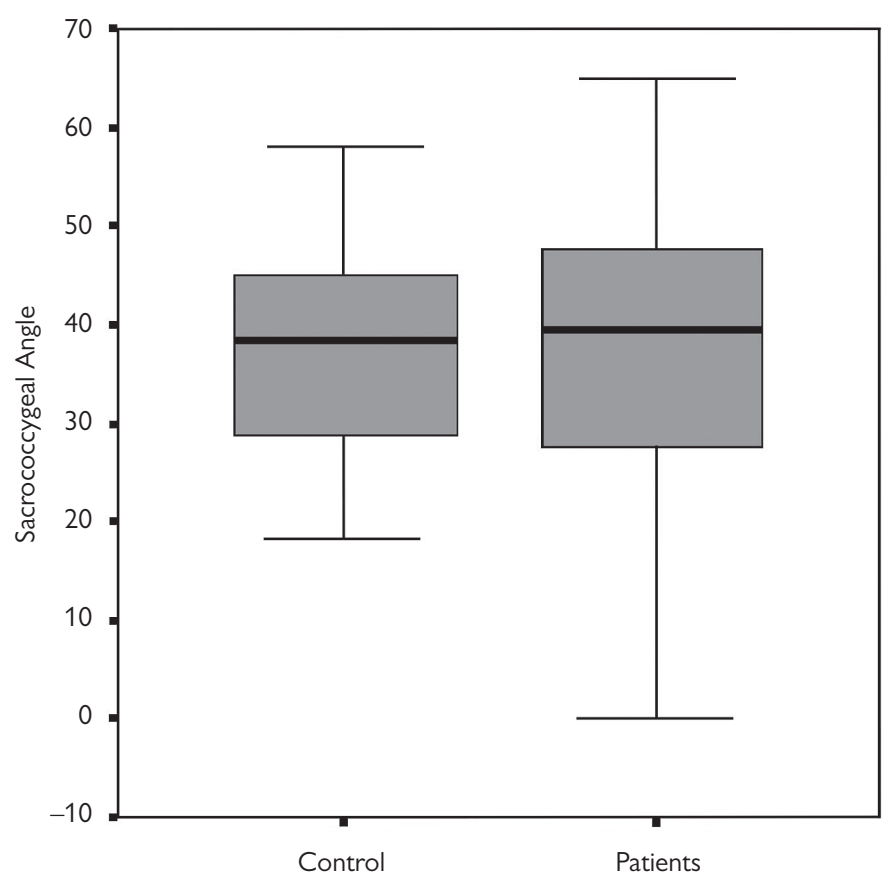

Figure 2 - Comparison of sacrococcygeal angle measurement values between patients and controls.

occurrence of disease in body parts where cutaneous folds are present such as axilla, umbilicus, penis, between fingers of barbers (Hull and Wu, 2002; Eryilmaz et al., 2005; Uysal et al., 2007) and existence of the disease among adults and the recurrence of the disease despite total excision of the related tissue (Raffman, 1959; Allen-Mersh, 1990; Hull and Wu, 2002; Chintapatla et al., 2003). Disease starts with the penetration of local hairs into subcutaneous tissue leading to the formation of chronic foreign body reaction (Patey and Scarff, 1948). The hairs are recognized as the main cause of the disease. There are many proposals how hair penetrates into subcutaneous layer and leads to pilonidal disease (Patey and Scarff, 1948; Raffman, 1959; Page, 1969; Bascom, 1980; Clothier and Haywood, 1984; Allen-Mersh, 1990; Hull and Wu, 2002). Karydakis (1992) underlined three factors playing a role in anchoring process of the hair:

1) Presence of skin debris and free hair which can invade skin in the area;

2) The force that causes insertion and penetration of hairs into the skin;

3) Vulnerability of the intergluteal sulcus (natal cleft) or other areas to invasion.

The disease starts with the separation of free hair from its follicle. It then accumulates in natal cleft. Invasion through the natal cleft occurs by friction and continuous irritation by other hairs eventually provokes a foreign body reaction. Subsequent inflammation and sometimes abscess formation leads to the development of sinuses. However, Bascom (1980) claimed another scenario where hair follicle is the main initiating factor of disease. The hair follicle obstruction 
leads to swelling and inflammation. Then it bursts to the subcutaneous tissue and forms a pilonidal abscess which eventually progresses to chronic sinus as a result of drainage.

Although the role of free hair for the development of pilonidal disease is acknowledged, several factors have been discussed for predisposition of the disease: hairy body and excessive daily hair loss, increase of vacuuming force applied on hairs and long stay period of fallen hairs due to narrow and deep natal cleft, facilitation of penetration of hairs as a result of skin which stays macerated and moisted for long time, crack, wound, or scar tissue in natal cleft, local trauma formation due to excessive period of sitting, poor hygiene (Raffman, 1959; Søndenaa et al., 1995; Akinci et al., 1999; Cubukcu et al., 2001; Hull and Wu, 2002; Chintapatla et al., 2003). By this, regularly shaving and cleansing of skin may decrease the formation of SPD.

While pilonidal disease was noticed more frequently in obese patients, the pathophysiological mechanism lying behind the association of obesity and the disease occurrence has not been elucidated yet (Akinci et al., 1999; Cubukcu et al., 2001; Sakr et al., 2003; Arda et al., 2005). The presence of SPD in lean patients also indicates that other factors play role in the etiology of the disease. Balik et al. (2006) reported higher amount of subcutaneous fat tissue in sacrococcygeal area among SPD patients. He explained that presence of higher fat content of sacrococcygeal area may help to deepen the intergluteal sulcus which traps more hairs for long time. Obviously any anatomical features of patient which contribute to deepen the intergluteal sulcus could be related with pilonidal disease formation. Since the skeletal frame in sacrococcygeal area could attribute to characteristic structure of intergluteal sulcus, we aimed to investigate whether sacrococcygeal angle differs in pilonidal disease patients. We hypothesized that narrower sacrococcygeal angle may cause deeper intergluteal sulcus. Actually, this was underscored earlier (Bascom, 1990). In the present study, no statistically significant difference in sacrococcygeal angle measurement was noted between SPD patients and the control group. The result might be explained with small number of patients especially if the expected difference is minute. Another possible explanation is that sacrococcygeal angle does not contribute to the depth of intergluteal sulcus.

In conclusion, the sacrococcygeal angle is not associated with pilonidal disease development. However, further investigations with assumed predisposing factors are needed.

\section{References}

Akinci, O. F., Bozer, M., Uzunköy, A., Düzgün, S. A., Coskun, A. (1999) Incidence and aetiological factors in pilonidal sinus among Turkish soldiers. Eur. J. Surg. 165, 339-342.

Allen-Mersh, T. G. (1990) Pilonidal sinus: finding the right tract for treatment. Br. J. Surg. 77, 123-132.

Arda, I. S., Güney, L. H., Sevmis, S., Hicsönmez, A. (2005) High body mass index as a possible risk factor for pilonidal sinus disease in adolescents. World J. Surg. 29, 469-471. 
Balik, O., Balik, A. A., Polat, K. Y., Aydinli, B., Kantarci, M., Aliagaoglu, C., Akcay, M. N. (2006) The importance of local subcutaneous fat thickness in pilonidal disease. Dis. Colon Rectum 49, 1755-1757.

Bascom, J. (1980) Pilonidal disease: origin from follicles of hairs and results of follicle removal as treatment. Surgery 87, 567-572.

Bascom, J. (1990) Pilonidal sinus. In: Current Therapy in Colon and Rectal Surgery. Fazio, V., Pp. 32-39, BC Decker, Toronto.

Chintapatla, S., Safarani, N., Kumar, S., Haboubi, N. (2003) Sacrococcygeal pilonidal sinus: historical review, pathological insight and surgical options. Tech. Coloproctol. 7, 3-8.

Clothier, P. R., Haywood, I. R. (1984) The natural history of the post anal (pilonidal) sinus. Ann. R. Coll. Surg. Engl. 66, 201-203.

Cubukcu, A., Carkman, S., Gönüllü, N. N., Alponat, A., Kayabasi, B., Eyüboglu, E. (2001) Lack of evidence that obesity is a cause of pilonidal sinus disease. Eur. J. Surg. 167, 297-298.

Eryilmaz, R., Sahin, M., Okan, I., Alimoglu, O., Somay, A. (2005) Umbilical pilonidal sinus disease: predisposing factors and treatment. World J. Surg. 29, 1158-1160.

Hull, T. L., Wu, J. (2002) Pilonidal disease. Surg. Clin. North Am. 82, 1169-1185.

Isik, A., Eryilmaz, R., Okan, I., Dasiran, F., Firat, D., Idiz, O., Sahin, M. (2014) The use of fibrin glue without surgery in the treatment of pilonidal sinus disease. Int. J. Clin. Exp. Med. 7, 1047-1051.

Karydakis, G. E. (1992) Easy and successful treatment of pilonidal sinus after explanation of its causative process. Aust. N. Z. J. Surg. 62, 385-389.

Mahdy, T. (2008) Surgical treatment of the pilonidal disease: primary closure or flap reconstruction after excision. Dis. Colon Rectum 51, 1816-1822.

McCallum, I., King, P. M., Bruce, J. (2007) Healing by primary versus secondary intention after surgical treatment for pilonidal sinus. Cochrane Database Syst. Rev. 4, CD006213.

Page, B. H. (1969) The entry of hair into a pilonidal sinus. Br. J. Surg. 56, 32.

Patey, D. H., Scarff, R.W. (1948) Pilonidal sinus in a barber's hand with observations on postanal pilonidal sinus. Lancet 2, 13.

Raffman, R. A. (1959) A re-evaluation of the pathogenesis of pilonidal sinus. Ann. Surg. 150, 895-903.

Tejirian, T., Lee, J. J., Abbas, M. A. (2007) Is wide local excision for pilonidal disease still justified? Am. Surg. 73 , 1075-1078.

Sakr, M., El-Hammadi, H., Moussa, A., Arafa, S., Rasheed, M. (2003) The effect of obesity on the results of Karydakis technique for the management of chronic pilonidal sinus. Int. J. Colorectal Dis. 18, 36-39.

Søndenaa, K., Andersen, E., Nesvik, I., Søreide, J. A. (1995) Patient characteristics and symptoms in chronic pilonidal sinus disease. Int. J. Colorectal Dis. 10, 39-42.

Uysal, A. C., Orbay, H., Uraloglu, M., Sensoz, O., Hyakusoku, H. (2007) Rare occupational disease of hair dressers: interdigital pilonidal sinus. J. Nippon Med. Sch. 74, 354-356.

Eryilmaz R.; Isik A.; Okan I.; Bilecik T.; Yekeler E.; Sahin M. 